\title{
Coefficient bounds in the class of functions associated with \$q-function theory
}

\author{
Krzysztof Piejko ${ }^{1}$, Janusz Sokół ${ }^{2}$, and Katarzyna Trabka-Wieclaw ${ }^{3}$ \\ ${ }^{1}$ Rzeszow University of Technology \\ ${ }^{2}$ University of Rzeszow \\ ${ }^{3}$ Lublin University of Technology
}

July 15, 2021

\begin{abstract}
In this paper, we use the concept of $\$ \mathrm{q} \$$-calculus in geometric function theory. For some $\$ \backslash$ alpha $\$$, $\$ \backslash$ alpha $\backslash$ in $[0,1) \$$, we consider normalized analytic functions $\$ \mathrm{f} \$$ such that $\$ \mathrm{f}^{\prime}(\mathrm{z}) /\{\backslash \mathrm{rm} \mathrm{d}\} \_\mathrm{qf}(\mathrm{z}) \$$ lies in half-plane $\$ \backslash\{\mathrm{w}: \backslash$ mathfrak $\{\operatorname{Re}\} \backslash \mathrm{w}>\backslash$ alpha $\backslash\} \$$ for all $\$ \mathrm{z} \$, \$|\mathrm{z}|<1 \$$. Here $\$\{\backslash \mathrm{rm} \mathrm{d}\}$ _q $\$$ is the Jackson $\$ \mathrm{q} \$$-derivative operator well-known in the $\$ \mathrm{q} \$$-calculus theory. The paper is devoted to the coefficient problems of such functions for real and for complex numbers $\$ \mathrm{q} \$$. Coefficient bounds are of particular interest, because of them some geometrical properties of the function can be obtained.
\end{abstract}

\section{Hosted file}

KPJS15.pdf available at https : //authorea.com/users/425819/articles/530533-coefficient-boundsin-the-class-of-functions-associated-with-q-function-theory 